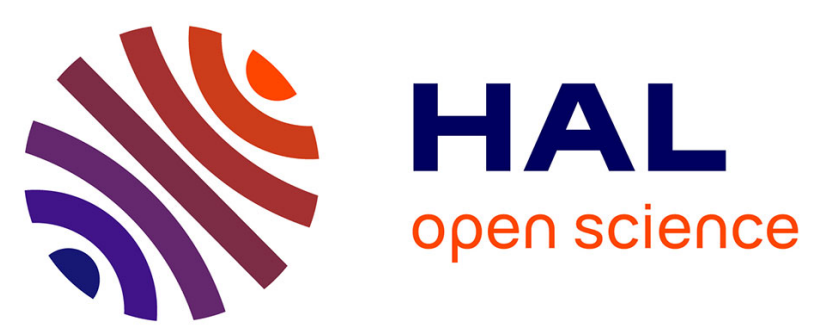

\title{
Combination of surface nanocrystallization and co-rolling: creating multilayer nanocrystalline composites
}

Laurent Waltz, Delphine Retraint, Arjen Roos, Patrick Olier, Jian Lu

\section{To cite this version:}

Laurent Waltz, Delphine Retraint, Arjen Roos, Patrick Olier, Jian Lu. Combination of surface nanocrystallization and co-rolling: creating multilayer nanocrystalline composites. Scripta Materialia, 2009, 60, pp.21-24. 10.1016/j.scriptamat.2008.08.024 . hal-00720643

\section{HAL Id: hal-00720643 \\ https://hal.science/hal-00720643}

Submitted on 25 Jul 2012

HAL is a multi-disciplinary open access archive for the deposit and dissemination of scientific research documents, whether they are published or not. The documents may come from teaching and research institutions in France or abroad, or from public or private research centers.
L'archive ouverte pluridisciplinaire HAL, est destinée au dépôt et à la diffusion de documents scientifiques de niveau recherche, publiés ou non, émanant des établissements d'enseignement et de recherche français ou étrangers, des laboratoires publics ou privés. 


\title{
Combination of surface nanocrystallization and co-rolling: creating multilayer nanocrystalline composites
}

\author{
L. Waltz ${ }^{\mathrm{a}}$, D. Retraint ${ }^{\mathrm{a},{ }^{*}}$, A. Roos ${ }^{\mathrm{a}}$, P. Olier ${ }^{\mathrm{b}}, \mathrm{J} \mathrm{Lu}^{\mathrm{c}}$ \\ ${ }^{a}$ Institute Charles Delaunay, FRE CNRS 2848, LASMIS, University of Technology of Troyes, \\ 10000 Troyes, France \\ ${ }^{b}$ DEN/DNM/SRMA/LTMEX, Commissariat à l'Energie Atomique de Saclay, 91191 Gif-sur-Yvette, France \\ ${ }^{c}$ Department of Mechanical Engineering, Hong Kong Polytechnic University, Hung Hom \\ Kowloon, Hong Kong
}

*Corresponding author: delphine.retraint@utt.fr

\begin{abstract}
This paper presents a combination of the surface mechanical attrition treatment (SMAT) and the corolling process performed at $550{ }^{\circ} \mathrm{C}$. This duplex method leads to the formation of a semi-massive multilayer structure of alternating nanocrystalline layers, transition layers and coarse grain layers. Transmission electron microscope observations correlated with nanoindentation hardness measurements demonstrated that grain size in the nano- and sub-nanocrystalline layers is preserved after the process. Tensile tests showed improved yield and ultimate strengths, and acceptable ductility.
\end{abstract}

Keywords: Nanocrystalline materials; SMAT; Co-rolling; Multilayered structure, Mechanical properties

\section{Introduction}

Materials presenting a microstructure in the nanometer grain size regime, i.e. characterized by a typical grain size of less than $100 \mathrm{~nm}$, have generated widespread interest during the last decade. Actually, nanocrystalline materials possess fundamentally different physical and chemical properties compared to their traditional polycrystalline coarse grain counterparts, and numerous studies on different nanocrystallized metals like iron, titanium, copper or stainless steel have shown an improved mechanical strength as well as excellent tribological and corrosion properties [1-11]. However, despite a high yield and ultimate strength, nanocrystallized materials exhibit a significantly lower ductility than their traditional coarse grain counterparts, which is directly linked to the volume fraction of the nanostructure in a material. Different kinds of electrochemical and mechanical techniques have been developed for producing massive nanocrystallized bulk materials, such as inert gas condensation, electrodeposition and severe plastic deformation (SPD). However, nanocrystalline structures synthesized with most of these techniques are not free of porosities and contamination, which remains an obstacle for industrial applications. Several authors have shown that a recently developed Surface Mechanical Attrition Treatment (SMAT) technique, based on mechanisms of severe plastic deformation, may induce a grain refinement down to the nanometer scale in the top surface layer of metallic materials and alloys, without contamination or porosity [1, 2-7, 8-10].

In the present paper, a method is presented which combines the superficial nanocrystalline treatment (SMAT) with the co-rolling process for the development of a semi-massive multilayered bulk structure. By optimizing the volume fraction of the nano-grains, this composite structure exhibits improved yield 
and ultimate tensile strengths, while conserving an acceptable elongation to failure. The alternating coarse grain layers and nanocrystallized layers are characterised by tensile tests and nanoindentations. Also, the microstructure is analysed by Transmission Electron Microscopy (TEM).

\section{Experimental procedures}

The material used in this investigation is a commercial $316 \mathrm{~L}$ face-centered cubic (fcc) austenitic stainless steel. For the experimental tests, $120 \times 120 \times 1 \mathrm{~mm}^{3}$ plates with the following chemical composition (in wt\%) 0.025 C, 0.38 Si, 1.33 Mn, 0.027 P, 0.002 S, 16.70 Cr, 2.09 Mo, 10.20 Ni, 0.030 $\mathrm{N}, 0.40 \mathrm{Cu}, 0.07 \mathrm{Co}$ were used. The initial microstructure of the as-received material is characterised by a grain size ranging between 40 and $120 \mu \mathrm{m}$. The surface nanocrystallization of these sheets was obtained by SMAT. The SMA-treatments have been performed in air at room temperature during 30 minutes, with $3 \mathrm{~mm}$ stainless steel shot, and at a vibration frequency of $20 \mathrm{kHz}$.

The co-rolling has been carried out at CEA on a reversible rolling mill with a maximal capacity of $3500 \mathrm{kN}$. The middle plate of the piling has been SMA-Treated on both sides, whereas the two other plates have been SMATed on their inner sides only (as depectited in Fig. 1). The choice of the rolling temperature $\left(550^{\circ} \mathrm{C}\right)$ results in a compromise which preserves the nanostructured layers but allows a possible bonding at the interfaces. The stack of treated sheets was co-rolled in two passes with a total thickness reduction of $55 \%$ corresponding to a total equivalent strain of 0,88 . Before each pass a preheating treatment was performed at $550^{\circ} \mathrm{C}$ during 90 minutes, and after the second pass, the material was water-cooled.

The microstructure of the co-rolled sample was characterized by means of TEM on a LEO 912 OMEGA microscope with an accelerating voltage of $120 \mathrm{kV}$. TEM plane-view specimens were cut from the co-rolled samples near the interface region. First, these specimens were mechanically polished down to a thickness of approximatively $90 \mu \mathrm{m}$. The electron transparency was then obtained by electropolishing using a twin-jet technique in a solution of $885 \mathrm{ml}$ buthanol, $590 \mathrm{ml}$ methanol and $90 \mathrm{ml}$ perchloric acid at a voltage of $25 \mathrm{~V}$ and a temperature of $-16^{\circ} \mathrm{C}$.

Tensile specimens with a total length of $36 \mathrm{~mm}$, a gauge length of $19 \mathrm{~mm}$ and an average cross section of $1.4 \times 3.6 \mathrm{~mm}^{2}$ were electrodischarge machined from the co-rolled sample. Tensile tests were performed at room temperature on a screw-driven Kammrath \& Weiss micro-tensile machine at a fixed strain rate of $10^{-4} \mathrm{~s}^{-1}$. After failure, the failure surfaces were analysed in a HITACHI S $3500 \mathrm{~N}$ scanning electron microscope (SEM).

In order to quantify the evolution of the local hardness through the cross-section of the co-rolled sample, nanoindentation measurements have been performed on a Nano Indenter $\mathrm{XP}^{\mathrm{TM}}$ fitted with a Berkovich diamond indenter. Furthermore, four indentations were put at the same distance from the upper surface in order to obtain a representative average value of the local hardness, as shown in the inset in Fig. 3. The indentation depths have been fixed at $600 \mathrm{~nm}$, and in order to avoid erroneous hardness measurements due to the affected plastic zone around an indentation, neighbouring indentations are separated by a distance of $20 \mu \mathrm{m}$ [12]. Before testing, the samples have been mechanically polished with 1200 grid silicon carbide papers and polished to mirror finish with alumina.

\section{Results and discussion}


Fig. 2 displays a bright-field TEM micrograph showing the microstructure of the co-rolled sample interface at a depth of about $450 \mu \mathrm{m}$ beneath the surface. By analysing this plane-view observation and its corresponding Selected Area Electron Diffraction (SAED) pattern, the microstructure in the interface region is characterized by ultrafine equiaxed grains with random crystallographic orientations. Taking into account several electron micrographs, the mean grain size is observed to range between 80 and 120 $\mathrm{nm}$. Despite some difficulties caused by the thinning technique used in this work and by flatness defects of the co-rolled laminate, a TEM specimen could be obtained from the ultrafine grained layer.

The results of local hardness measurements obtained by nanoindentation through the cross-section of the co-rolled multilayer laminate are shown in Fig. 3. The inset at the top right hand corner gives an illustration of the distribution of the different indentations through the cross-section of the sample. In this figure it can be observed that the co-rolling process considerably enhances the local hardness of the coarse grain matrix layers to about 4.2 GPa. This value is approximately 1.8 times higher than the initial hardness of the coarse grain plate, and can be explained by the high work hardening occurring during the rolling process. Furthermore, the local hardness gradually increases and tends towards a maximum value of $9.2 \mathrm{GPa}$ near the first interface of the laminate, at a depth of about $465 \mu \mathrm{m}$ below the surface, which is approximately four times higher than the initial coarse grain hardness. This hardness level is comparable to the microhardness of nanocrystallized tungsten obtained by high-pressure torsion (about $11 \mathrm{GPa})$ [13], in severe plastic deformed steel [14] or in some hard ceramics. For comparison, nanoindentation measurements have been performed over the cross section of a co-rolled steak of three plates without SMAT rolled with the same reduction ratio and at the same temperature as the SMATed one. Despite a similar work hardening level, the distribution of the local hardness of this specimen stays more homogeneous. Indeed, a constant hardness value of about $4.2 \mathrm{GPa}$ is obtained throughout the thickness of this specimen, and no significant hardness increase can be recorded near the interface regions or at the free edges. Accordingly to the studies of S.H. Lee et al [15-16] and B.L. Li et al [17] concerning the accumulative roll-bonding of aluminium, the absence of hardness increase in the interface region indicates that the work hardening induced by friction shear strain during co-rolling is negligible, and therefore, we can assume that no significant shear induced microstructural changes take place during co-rolling. So, the inhomogeneity of the hardness recorded for the co-rolled multilayer structure (Fig. 3) can be entirely attributed to the presence of a SMAT induced grain size gradient from the treated top surface to the deep matrix of the treated sample. As mentioned in the literature, this grain size gradient is directly linked with the distribution of the important SMAT-induced strain and strain rate throughout the thickness of treated specimens. The grain refinement underlying mechanism and hardening process occurring during SMA-Treatment are described in details by J. Lu et al [10] for different materials with different stacking fault energies (SFE). Furthermore, a linkage between the grain size and the hardness through a normal Hall-Petch relationship has been observed by T. Roland et al [7] and Jian et al [10]. Therefore, the hardness distribution of the co-rolled nanocrystallized multilayer structure indicates that the high hardness values in the interface regions can be explained by the presence of nanocrystallites, whose presence are confirmed by TEM images (see Fig. 2). However, the hardness level reached in the coarse grain matrix $(\approx 4.2 \mathrm{GPa})$ is only an effect of the high work hardening induced during the process, since the average grain size recorded in this region remains unchanged from the coarse grain state (hardness of $\approx 2.4 \mathrm{GPa}$ ). The only difference is related to the morphology of the grains, which are more elongated in the co-rolled sample. Throughout the transition layer, the hardness increase an reach a maximum in the nanocrystallized layer which is characteristic of a grain size refinement in these regions, in accordance with the Hall-Petch law. So, referring to the TEM images obtained in this work and by T. Roland in his studies about 316L stainless steel [7], we can not a grain size reduction from several teens of micrometer in the coarse grain matrix to several teens of nanometer 
in the nanocristallized layer. In addition, it is noteworthy that a small part of the local hardness increase in the nanocrystalline layer at the top surface of SMATed samples, or at the interfaces of our co-rolled sample, may be attributed to the presence of a strain induced martensite phase [4-7].

The tensile engineering stress-strain curves of a co-rolled nanocrystallized multilayer laminate and of a co-rolled steak of three plates without SMAT (reduction ratio of $55 \%$ and rolled at $550{ }^{\circ} \mathrm{C}$ ) are shown in Fig. 4. For comparison, the stress-strain curve of an as-received coarse grain specimen with the same cross-section area is also included in this figure. Noteworthy observations from these plots are that the co-rolled multilayer structure shows significantly high values of yield and ultimate strength. The yield strength ( $0.2 \%$ offset) reaches a value as high as $750 \mathrm{MPa}$, which corresponds to an increase of about $154 \%$ compared to the coarse grain sample (295 MPa), and an ultimate strength of $860 \mathrm{MPa}$. One can also note that the strength levels of the co-rolled specimen are enhanced with respect to the co-rolled sample without SMAT, because yield and ultimate strengths are higher by about 13\% and 15\%, respectively. The high strength of the co-rolled multilayer laminate can be explained by an increased of the volume fraction of nano and ultrafine grains as described in the literature [1-2, 5-7], because nanocrystalline layers are able to sustain an important part of the load. Indeed, an increase of the volume fraction of nano grains of about 5\% in the co-rolled structure SMATed at the interfaces leads thus to an appreciable yield strength increase of about $100 \mathrm{MPa}$ in comparison of the co-rolled sample without SAMT. Furthermore, despite the increased volume fraction of nanograins and the strain hardening induced by the rolling process, the laminate shows an acceptable ductility of approximately $13 \%$.

Fig. 5 a) shows an example of the fracture surface of the co-rolled multilayer tensile specimen after the tensile test: the three sheets of the laminate stack can be clearly observed. It can be noted that this sample failed with an obvious macroscopic necking. Furthermore, the fracture morphology of this sample presents a significant feature, since on the two lateral sheets, initially SMATed on their inner sides, one can clearly distinguish two distinct failure structures. Indeed, Fig. 5 c) presents a high magnification SEM micrograph of this area, showing a clear and straight separation between the two regions, both characterized by a specific failure mode. It is interesting to note that the flat fracture surface region near the interface (Fig. 5 c) and 5 d)), which corresponds to the initially nanostructured and refined structure layer after SMAT [5-7, 10], looks like a glassy brittle material. Chen et al. [18] reported a similar brittle failure mode in a $15 \mu \mathrm{m}$ thick nanocrystallized $316 \mathrm{~L}$ austenitic stainless steel tensile sample. Contrary to this, the outer side of this sheet presents a heavily dimpled and rough morphology (Fig. 5 b)), suggesting that this part of the specimen has been torn apart in a ductile manner and has been contributing actively to the observed plasticity in Fig. 4. Thus, as mentioned before, the difference in the underlying fracture mechanism, observed principally on the two outer plates, can be related to multilayer aspect of the microstructure in the specimen.

\section{Conclusions}

In the present study, generation of a high strength semi-massive structure by a combination of the surface mechanical attrition treatment (SMAT) and the co-rolling process at high temperature has been investigated. A multilayered composite laminate alternating nanocrystalline layers, transition layers and coarse grain layers was successfully developed. Process parameters used in this work have shown good interface welding of the co-rolled laminate, despite some boundary effects induced by the rolling process. TEM observations performed near the interface region and local hardness measurements by nanoindentation have shown that the nano- and sub-nanocrystalline layers are conserved after hot corolling, and that the grain growth remains limited. Furthermore, the new developed structure presents 
improved yield and ultimate strengths $(710 \mathrm{MPa}$ and $860 \mathrm{MPa}$ respectively), while keeping an acceptable plastic strain to failure of approximately $13 \%$. Finally, the fracture morphology of the corolled multilayer laminate suggests that the failure occurs in a combined ductile-brittle manner. This can be explained by the multilayer aspect of the microstructure in the cross-section of the laminate.

\section{Acknowledgements}

The authors thank Prof. Pentti Karjalainen from the Materials Engineering Laboratory at the University of Oulu for supplying the transmission electron microscopy equipment and for helpful discussions.

\section{References}

[1] Y.M. Wang, K. Wang, D. Pan, K. Lu, K.J. Hemker, E. Ma, Scripta Mater. 48 (2003) 1581-1586.

[2] J. Chen, L. Lu, K. Lu, Scripta Mater. 54 (2006) 1913-1918.

[3] G. Liu, J. Lu, K. Lu, Mater. Sci. Eng. A286 (2000) 91-95.

[4] H.W. Zhang, Z.K. Hei, G. Liu, J. Lu, K. Lu, Acta Mater. 51 (2003) 1871-1881.

[5] T. Roland, Ph.D. Thesis, University of Technology of Troyes (2006).

[6] T. Roland, M. Ya, D. Retraint, K. Lu, J. Lu, Journal of Mater. Sci. Tech. 20 (2004) 55-58.

[7] T. Roland, D. Retraint, K. Lu, J. Lu, Mater. Sci. Eng. A445-446 (2007) 281-288.

[8] N.R. Tao, M.L. Sui, J. Lu, K. Lu, Acta Met. 11 (1999) 443-440.

[9] N.R. Tao, Z.B. Wang, W.P. Tong, M.L. Sui, J. Lu, K. Lu, Acta Mater. 50 (2002) 4603-4616.

[10] J. Lu, K. Lu, Comprehensive Structural Integrity, Fracture of Materials from Nano to Macro 8 (2005) 1039-1044.

[11] K.S. Kumar, S. Suresh, M.F. Chisholm, J.A. Horton, P. Wang, Acta Mater. 51 (2003) 387-405.

[12] J.L. Hay, G.M. Pharr, Instrumented Indentation Testing, ASM Handbook 8 (2000) 232-243.

[13] Q. Wei, H.T. Zhang, B.E. Schuster, K.T. Ramesh, R.Z. Valiev, L.J. Kecskes, R.J. Dowding, L. Magness, K. Cho, Acta Mater. 54 (2006) 4079-4089.

[14] M. Umemoto, Mater. Trans. 44 (10) (2003) 1900-1911.

[15] S.H. Lee, Y. Saito, N. Tsuji, H. Utsunomiya, T. Sakai, Scripta Mater. 46 (2002) 281-285.

[16] S.H. Lee, Y. Saito, T. Sakai, H. Utsunomiya, Mater. Sci. Eng. A325 (2002) 228-235.

[17] B.L. Li, N. Tsuji, N. Kamikawa, Mater. Sci. Eng. A423 (2006) 331-342.

[18] X.H. Chen, J. Lu, L. Lu, K. Lu, Scripta Mater. 52 (2005) 1039-1044. 


\begin{tabular}{|c|c|}
\hline First step: & $\begin{array}{c}\text { Second step: } \\
\text { - Ultrasonic-assisted SMAT } \\
\text { - Assembly of three treated plates }\end{array}$ \\
\end{tabular}

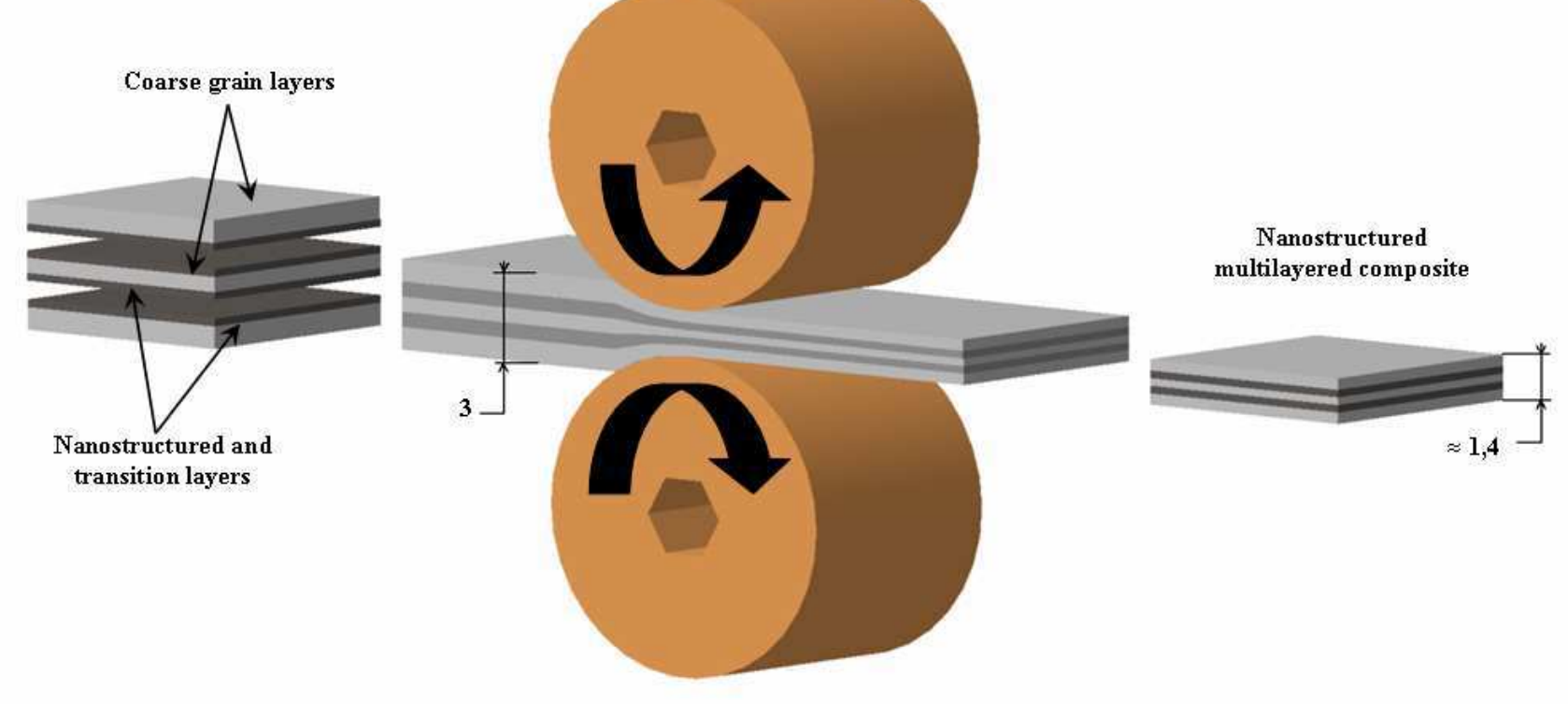

Fig. 1: Illustration of the co-rolling process of three SMATed plates. 


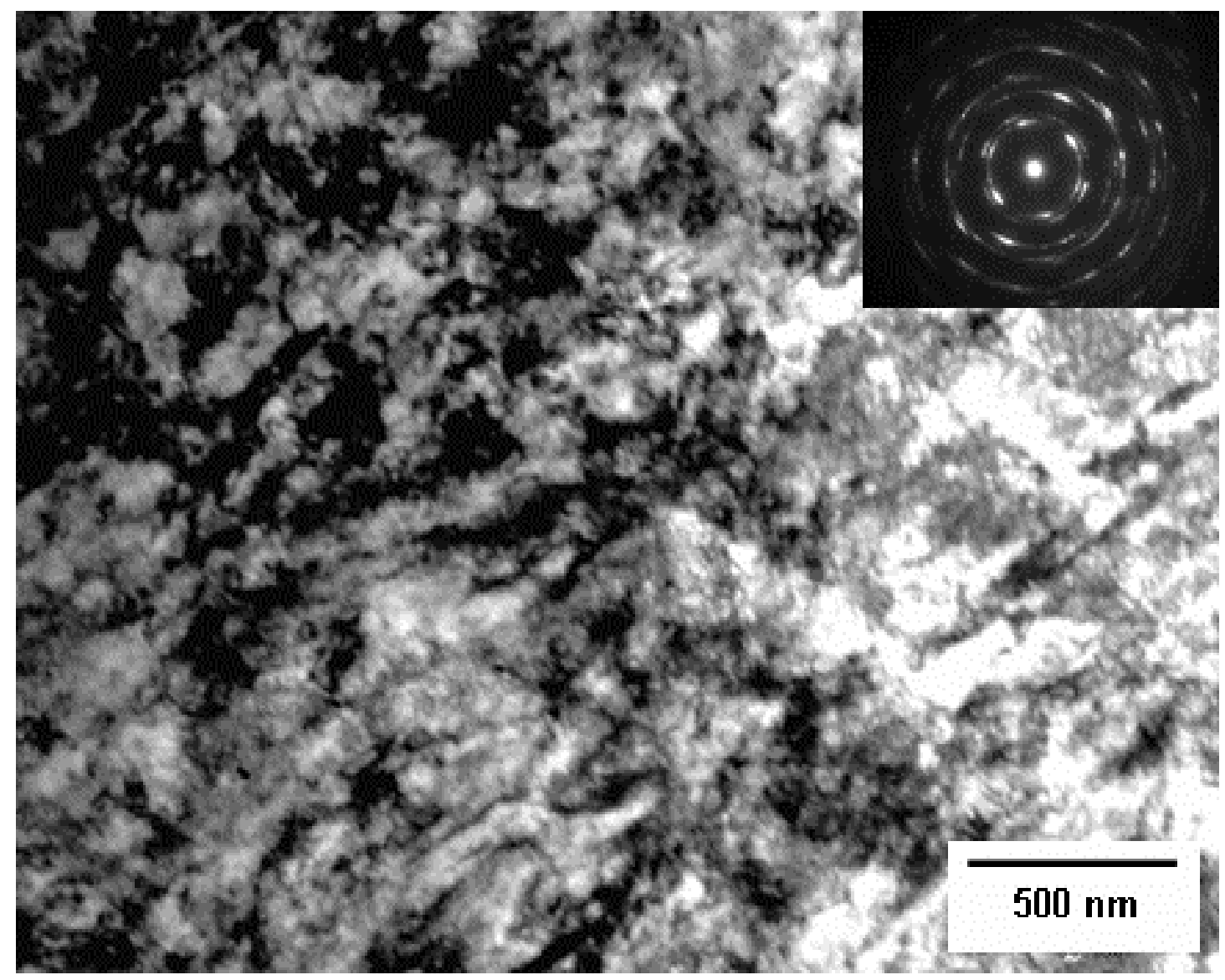

Fig. 2: Bright-field TEM image and the corresponding SAED pattern of the sub-nanocrystalline layer near the interface at a depth of about $450 \mu \mathrm{m}$ (rectangular box in Fig. 2). 


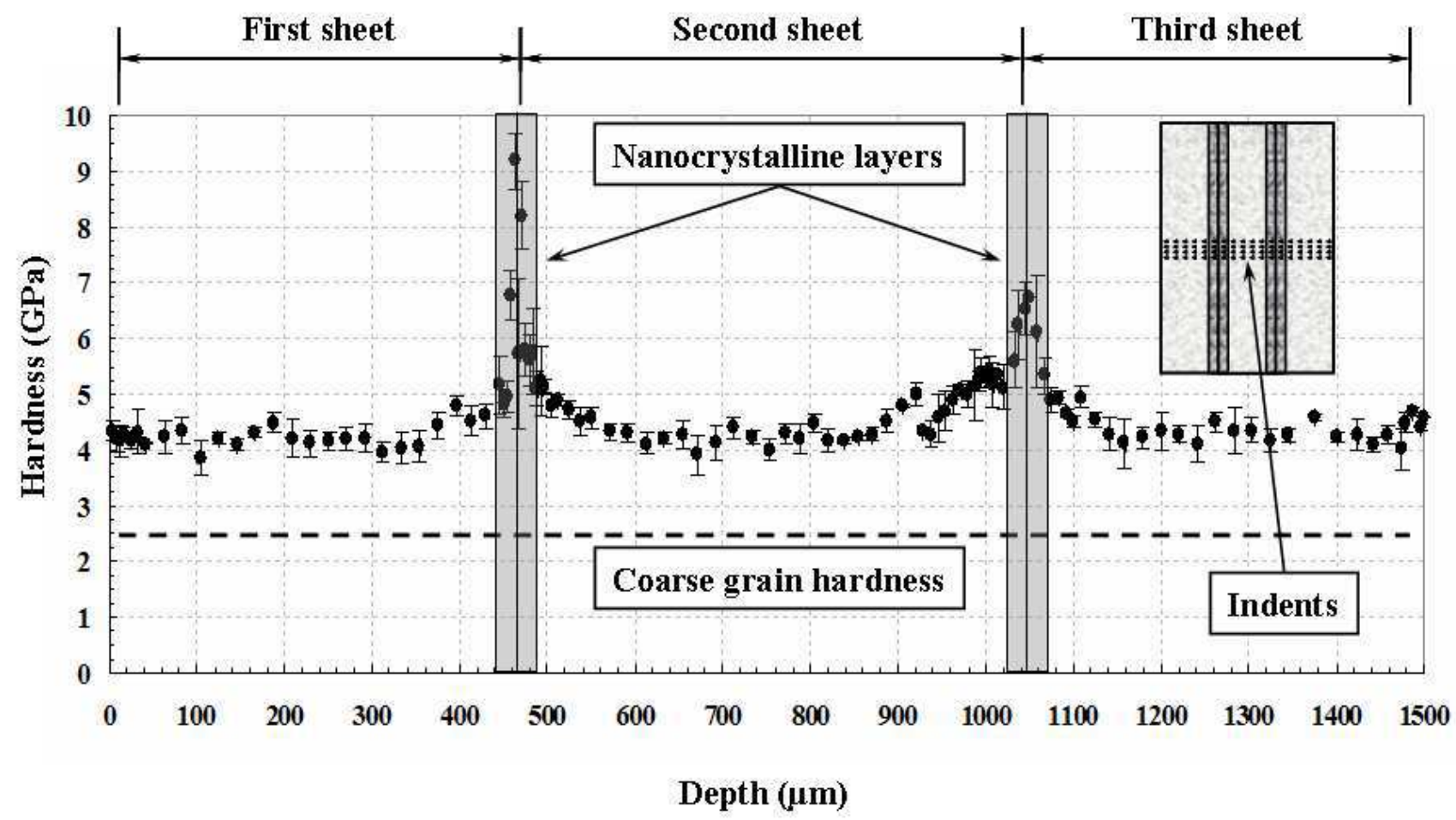

Fig. 3: Local hardness evolution through the cross-section of the co-rolled multilayer sample. 


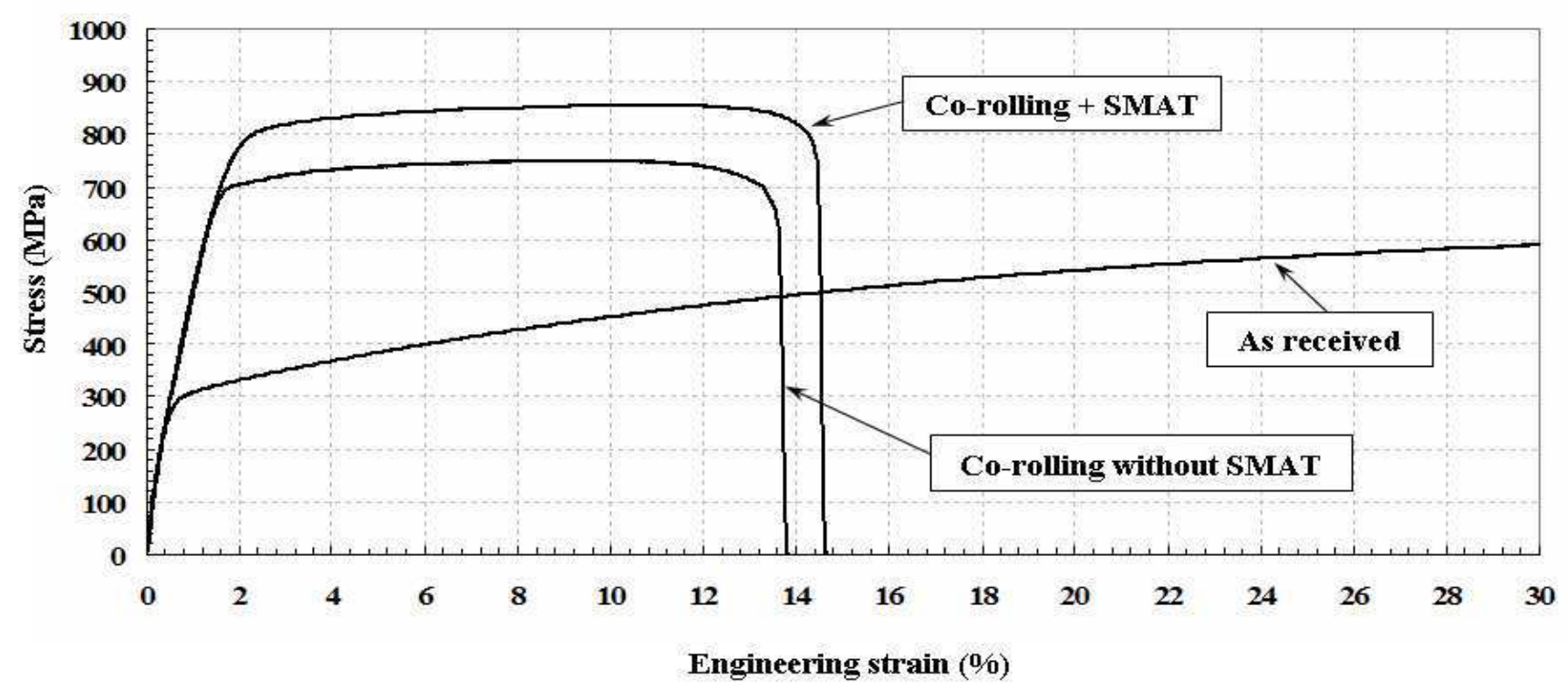

Fig. 4: Uniaxial engineering tensile stress-strain curves of a co-rolled SMATed multilayer specimen, a cold rolled sample without SMAT and an as-received coarse grain sample. 


\section{a)}

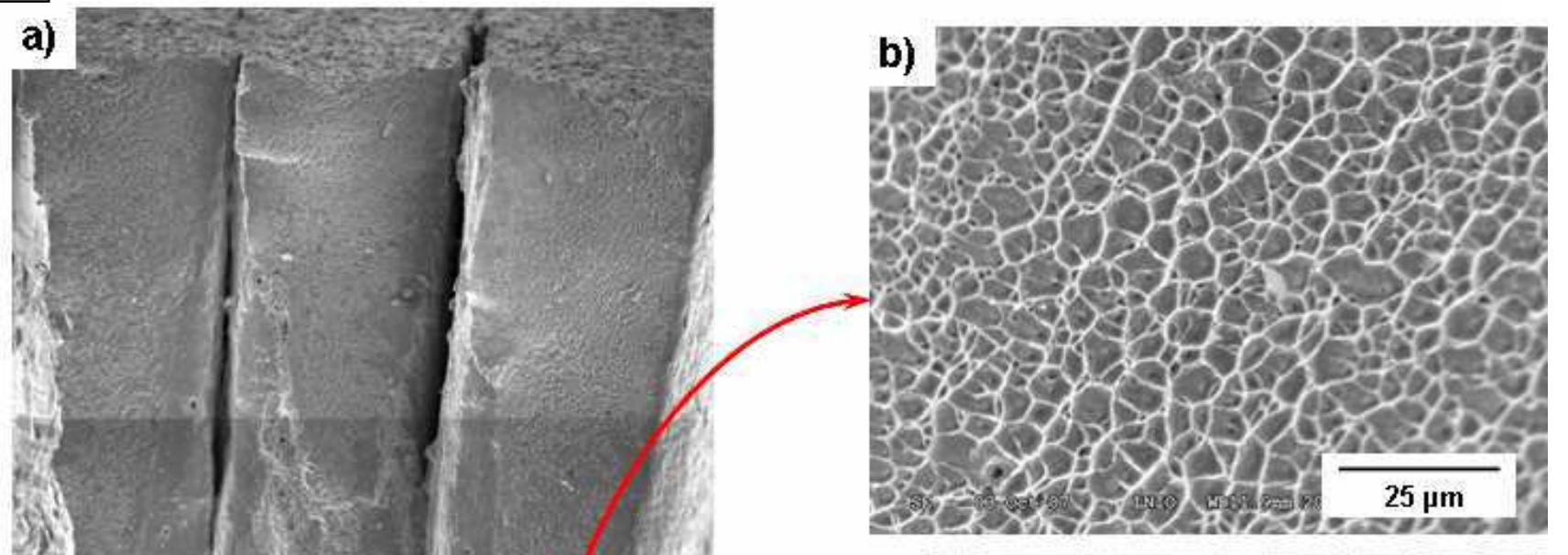

is
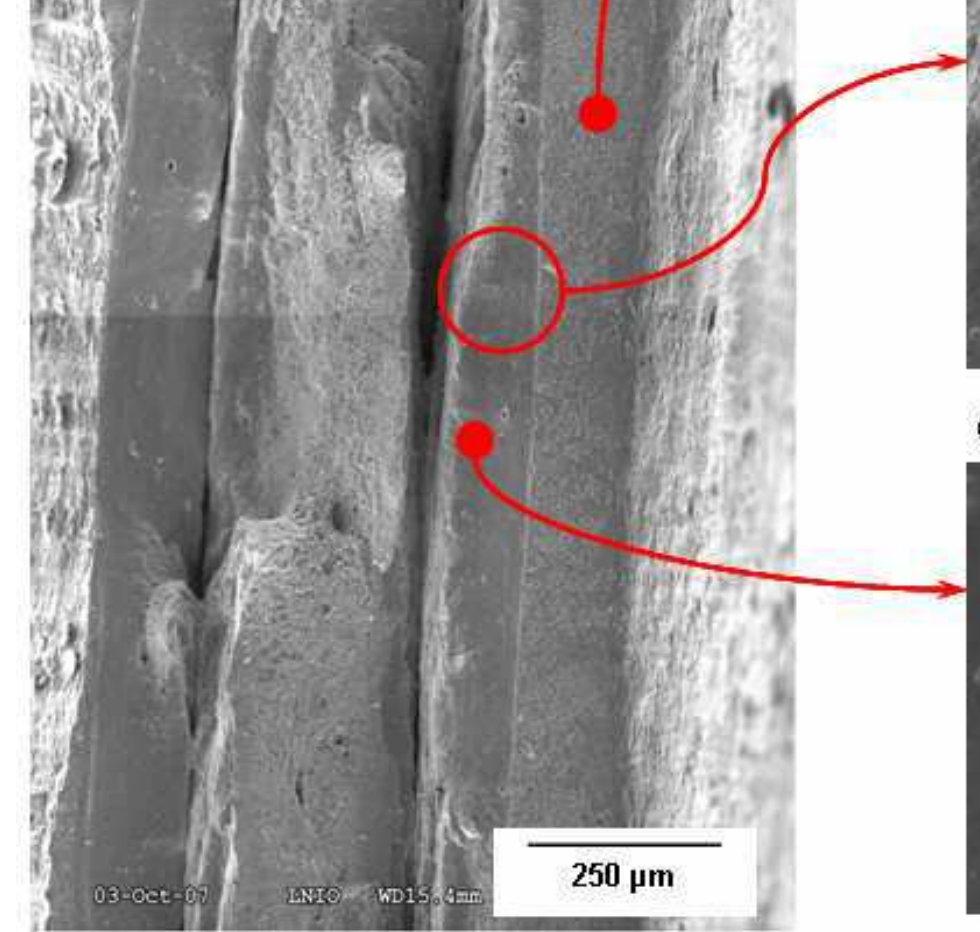

\section{c)}
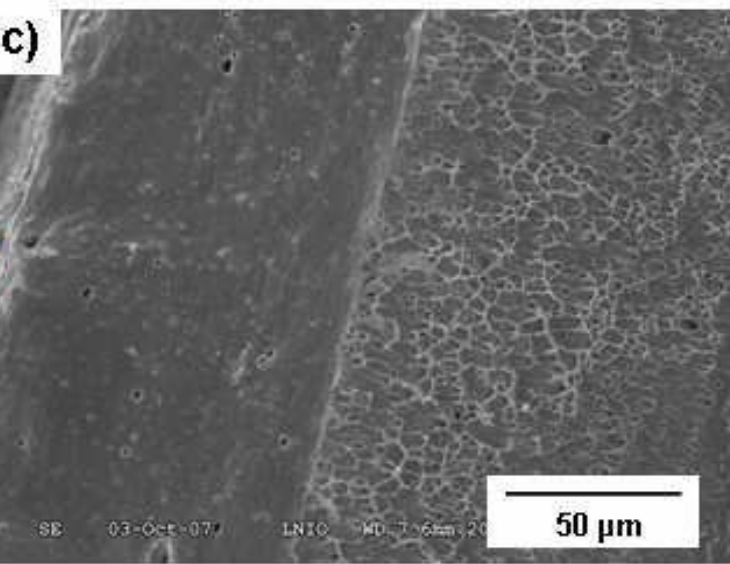

d)

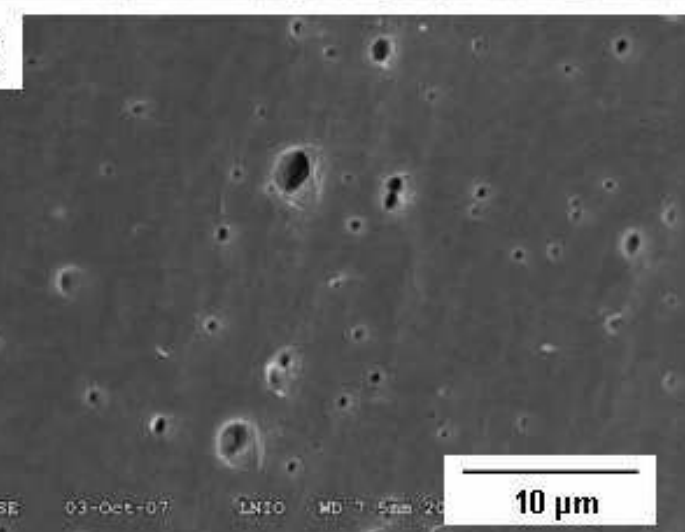

Fig. 5: a) SEM micrographs of the fracture surface of the co-rolled multilayer tensile specimen; b), c) and d) high magnification SEM micrographs of selected regions. 